\title{
The combination of axitinib followed by paclitaxel/carboplatin yields extended survival in advanced BRAF wild-type melanoma: results of a clinical/correlative prospective phase II clinical trial
}

A P Algazi ${ }^{1}$, E Cha ${ }^{1}$, S M Ortiz-Urda ${ }^{2}, \mathrm{~T} \mathrm{McCalmont}^{2}, \mathrm{~B}$ C Bastian ${ }^{2}, \mathrm{~J} \mathrm{Hwang}^{1}, \mathrm{M} \mathrm{H} \mathrm{Pampaloni}{ }^{3}, \mathrm{~S} \mathrm{Behr}^{3}$, K Chong ${ }^{2}$, B Cortez $^{1}$, A Quiroz ${ }^{1}$, F Coakley ${ }^{4}, \mathrm{~S} \mathrm{Liu}^{4}$ and A I Daud ${ }^{*, 1}$

${ }^{1}$ Department of Medicine, Division of Hematology/Oncology, University of California, 1600 Divisadero St MTZ-A741, San Francisco, CA 94143-1770, USA; ${ }^{2}$ Department of Dermatology, University of California, 1600 Divisadero St MTZ-A741, San Francisco, CA 94143-1770, USA; ${ }^{3}$ Department of Nuclear Medicine, University of California, 1600 Divisadero St MTZ-A741, San Francisco, CA 94143-1770, USA and ${ }^{4}$ Department of Radiology, University of California, 1600 Divisadero St MTZ-A741, San Francisco, CA 94143-1770, USA

Background: Simultaneous chemotherapy with vascular endothelial growth factor (VEGF) inhibition has not shown additional benefit over chemotherapy alone in advanced melanoma. We tested administration of the potent VEGF inhibitor axitinib followed by paclitaxel/carboplatin to determine whether enhanced tumour proliferation during axitinib withdrawal leads to sustained chemosensitivity.

Methods: We conducted a prospective phase II trial in metastatic melanoma patients with ECOG performance status 0-1 and normal organ function. Axitinib $5 \mathrm{mg}$ PO b.i.d. was taken on days 1-14 of each 21-day treatment cycle, and carboplatin $(A \cup C=5)$ with paclitaxel $\left(175 \mathrm{mg} \mathrm{m}^{-2}\right)$ was administered on day 1 starting with cycle $2.3^{\prime}$-Deoxy- $3^{\prime}-{ }^{18} \mathrm{~F}$-fluorothymidine $\left({ }^{18} \mathrm{~F}\right.$-FLT)-PET scans were performed in five patients to assess tumour proliferation on days 1, 14, 17, and 20 of cycle 1. Molecular profiling for BRAF was performed for all patients with cutaneous, acral, or mucosal melanoma.

Results: The treatment was well tolerated. The most common grade 3 AEs were hypertension, neutropenia, and anaemia. Grade 4 non-haematologic AEs were not observed. Four of five patients completing ${ }^{18}$ F-FLT-PET scans showed increases (23-92\%) in SUV values during the axitinib holiday. Of 36 evaluable patients, there were 8 confirmed PRs by Response Evaluation Criteria in Solid Tumors. Overall, 20 patients had SD and 8 had PD as the best response. The median PFS was 8.7 months and the median overall survival was 14.0 months. Five BRAF ${ }^{\mathrm{V} 600 \mathrm{E} / \mathrm{K}}$ patients had significantly worse PFS than patients without these mutations.

Conclusions: Axitinib followed by carboplatin and paclitaxel was well tolerated and effective in BRAF wild-type metastatic melanoma. $3^{\prime}-$ Deoxy- $3^{\prime}-{ }^{18} \mathrm{~F}$-fluorothymidine-PET scans showed increased proliferation during axitinib withdrawal.

*Correspondence: Professor Al Daud; E-mail: adil.daud@ucsf.edu

Portions of the study presented at the 2011 and 2012 ASCO Annual Meetings.

Received 6 November 2013; revised 22 July 2014; accepted 8 September 2014; published online 31 March 2015 (c) 2015 Cancer Research UK. All rights reserved 0007-0920/15 
Metastatic melanoma is an aggressive malignancy that claims over 8000 lives in the United States annually (Jemal et al, 2010). The development of potent, selective BRAF inhibitors has revolutionised the treatment of patients with melanoma harbouring activating $\mathrm{BRAF}^{\mathrm{V} 600 \mathrm{E}}$ and $\mathrm{BRAF}^{\mathrm{V} 600 \mathrm{~K}}$ mutations (Flaherty et al, 2010; Chapman et al, 2011; Falchook et al, 2012; Sosman et al, 2012). However, patients whose tumours do not have BRAF mutations, $\sim 50 \%$ of all melanoma patients, have fewer options. These include the anti-CTLA4 antibody, ipilimumab, which has a relatively low response rate and modest survival benefits for most patients (Hodi et al, 2010; Robert et al, 2011), and chemotherapy alone (Algazi et al, 2010), which has an unclear survival benefit. Thus, additional treatment options for these patients are urgently needed.

Agents targeting vascular endothelial growth factor (VEGF) signalling have demonstrated efficacy in multiple solid tumours including colorectal carcinoma (Hurwitz et al, 2004; Saltz et al, 2008), non-small cell lung cancer (Sandler et al, 2006), renal cell carcinoma (Motzer et al, 2009; Rini et al, 2011), and ovarian cancer (Perren et al, 2011), often in combination with cytotoxic chemotherapy. Melanoma metastases express high levels of VEGF (Salven et al, 1997; Ugurel et al, 2001; Demirkesen et al, 2006), increased VEGF signalling is associated with increased tumour cell survival (Graells et al, 2004), and VEGF inhibition arrests tumour growth in melanoma xenografts (Oku et al, 1998). However, results of large clinical trials targeting VEGF in combination with chemotherapy have been disappointing. For example, a randomised phase III trial of carboplatin and paclitaxel with and without sorafenib, which targets VEGF receptors 1, 2, and 3, demonstrated no improvement in objective tumour response, progression-free survival (PFS), or overall survival (OS) with the addition of sorafenib to chemotherapy (Hauschild et al, 2009).

Axitinib is a highly potent, selective inhibitor of VEGF 1, 2, and 3 with substantial single-agent activity in melanoma (Fruehauf et al, 2011). In phase II testing, axitinib induced objective tumour response in $18.8 \%$ of patients with a median PFS of 3.9 months and a median OS of 6.2 months. We conducted a prospective, singlearm, phase II study of axitinib dosing in combination with carboplatin and paclitaxel, a commonly used cytotoxic regimen in metastatic melanoma (Rao et al, 2006; Hauschild et al, 2009; Kim et al, 2012). Our hypothesis is that administration of axitinib with carboplatin and paclitaxel leads to prolonged PFS. We also explored whether interruptions in axitinib dosing increased tumour proliferation using $3^{\prime}$-deoxy- $3^{\prime}-{ }^{18} \mathrm{~F}$-fluorothymidine $\left({ }^{18} \mathrm{~F}\right.$ FLT)-PET imaging. This is based on recent clinical ${ }^{18}$ F-FLT-PET data suggesting that VEGF inhibition may decrease tumour proliferation thereby decreasing the efficacy of cytotoxic agents (Hoh et al, 2011). If confirmed, these findings would suggest that interruptions in dosing of axitinib could enhance the efficacy of combination therapy.

\section{MATERIALS AND METHODS}

Study design. This was a prospective, single-arm, phase II clinical trial. The Scientific Review Committee and Institutional Review Board at the University of California, San Francisco, CA, USA approved the trial. Accrual began in August 2010 and was completed in February 2012.

Patients. Eligible patients had histologically or cytologically confirmed stage IV or unresectable stage III melanoma. Patients were required to have an ECOG performance status of 0 or 1; adequate bone marrow function (including an absolute neutrophil count $\geqslant 1.5 \times 10^{9} \mathrm{l}^{-1}$, haemoglobin $\geqslant 9 \mathrm{~g} \mathrm{dl}^{-1}$, and platelets $\geqslant 100 \times 10^{9} 1^{-1}$ ): and adequate renal (creatinine $\leqslant 1.5$ times the upper limit of normal), and hepatic function (total bilirubin $\leqslant 1.5$ times the upper limit of normal, AST and ALT $\leqslant 2.5$ times the upper limit of normal or $\leqslant 5$ times the upper limit of normal liver function abnormalities were due to underlying malignancy). Patients with uncontrolled hypertension were excluded as were patients with a history of haemoptysis or GI bleeding, a history of abdominal fistula or perforation, or a history of significant cardiovascular events within the past 6 months. Up to three prior lines of therapy were enrolled as long as these did not include carboplatin or paclitaxel. Patients with treated brain metastases were allowed as long as these had been stable for at least 4 weeks.

Study treatment. Patients started with axitinib $5 \mathrm{mg}$ by mouth twice daily on days 1-14 of each 21-day cycle. Subsequently, on cycle $\geqslant 2$, day 1 patients received carboplatin $(A U C=5)$ with paclitaxel $\left(175 \mathrm{mg} \mathrm{m}^{-2}\right)$ with axitinib dosed days $1-14$ as in cycle 1. Dose reductions of all study drugs were made for significant treatment associated toxicities including severe neutropenia, febrile neutropenia, or thrombocytopenia. Patients completing $\geqslant 6$ cycles of chemotherapy were offered axitinib monotherapy with continuous daily dosing at the discretion of the patient and the investigator. Treatment was discontinued for patients requiring more than two dose reductions. Adverse events were graded using the Common Terminology Criteria for Adverse Events version 4.0.

$3^{\prime}$-Deoxy- $3^{\prime}{ }_{-}^{18}$ F-fluorothymidine-PET imaging. $3^{\prime}$-Deoxy- $3{ }^{\prime}-{ }^{18} \mathrm{~F}$ fluorothymidine -PET/CT images were acquired from vertex to toes $45-60 \mathrm{~min}$ after IV administration of $160-195 \mathrm{MBq}$ of ${ }^{18} \mathrm{~F}-\mathrm{FLT}$. The axial field of view covered $14.5 \mathrm{~cm}$, with an axial sampling thickness of $5 \mathrm{~mm}$ per slice. A whole-body noncontrast-enhanced CT scan was also acquired using either a Siemens Biograph (Siemens Medical Solutions USA, Inc., Malvern, PA, USA) or a GE VCT 64detector helical CT system (GE Medical Systems, Waukesha, WI, USA) for anatomic localisation and attenuation correction. The following parameters were used: $130 \mathrm{kVp}, 120 \mathrm{~mA}, 1$-s tube rotation, 5-mm slice collimation. All PET images were analysed quantitatively by measuring the maximal standardised uptake values $\left(\mathrm{SUV}_{\max }\right)$ and compared with non-affected lymphoid organs and the mediastinal blood pool. The single maximum pixel value within the one slice with the highest radioactivity concentration was detected $\left(\mathrm{SUV}_{\max }\right)$ The sum of target lesion $\mathrm{SUV}_{\max }$ values was calculated for each patient at each time point and these sums were compared across time points for each patient.

Response assessment and statistics. Tumour responses were evaluated after the completion of 9 weeks of treatment and every 6 weeks thereafter by an independent, unblinded radiologist using the Response Evaluation Criteria in Solid Tumors version 1.1 (Eisenhauer et al, 2009). Partial and complete responses were confirmed at least 4 weeks after the initial response. The estimated objective response rate for the therapeutic combination was calculated with a 95\% confidence interval (CI) using the exact binomial distribution. Stable disease was defined as the absence of objective response and the absence of disease progression for at least 13 weeks ( 3 months). The OS and PFS were estimated using the Kaplan-Meier method (Kaplan and Meier, 1958). Post hoc subgroup comparisons were made using the log-rank test. No adjustment was made for multiple comparisons given the exploratory nature of these tests. The statistical software package SPSS (IBM North America, New York, NY, USA) was used to compute trial results.

Genotyping and subgroup analysis. BRAF mutation detection was performed by Sanger sequencing of exon 15 in forward and reverse direction for all patients, with the exception of patients with uveal melanoma. Mutation testing of NRAS (exons 1 and 2), GNAQ and GNA11 (exon 5), and KIT (exons 9, 11, 13, 17, and 18) was performed depending on the BRAF mutation status and the clinical context. 


\section{RESULTS}

Patients and treatment. A total of 40 patients with advanced melanoma were consented for this study. Two patients were lost to follow-up before a single cycle could be completed and hence were not included in the analyses. Patient characteristics for the remaining 38 patients are described in Table 1 . Two additional patients with cutaneous melanoma discontinued treatment due to toxicity within the first 3 weeks, before the first infusion of paclitaxel/carboplatin. Both of these patients were considered to be evaluable for toxicity but not for response. One patient developed a congestive heart failure exacerbation within the first 2 weeks of receiving axitinib. A second patient had baseline pancytopenia, which worsened with 2 weeks of axitinib monotherapy. In total, 36 patients were considered to be evaluable for both toxicity and response. Of these 36 patients, 25 were treatment naive, 7 had one prior line of therapy, 2 had two prior lines of therapy, and 2 had three prior lines of therapy. Among the 36 evaluable patients, 14 opted to pursue continuous axitinib monotherapy after an average of 8.1 months ( \pm 3.6 months).

Toxicity. The most common grade 3 and 4 toxicities were haematologic with eight patients $(21 \%)$ developing grade 3 or 4 neutropenia, one patient with febrile neutropenia, two patients (5\%) with grade 3 thrombocytopenia, and one patient (3\%) developing grade 3 anaemia. Additional grade 3 and 4 adverse events included grade 3 hypertension in six patients (16\%), oral mucositis, and syncope. One patient developed congestive heart



failure after 9 days of treatment with axitinib alone. The patient's symptoms resolved to baseline with medical management and he died 2 months later from progression of melanoma. Overall, 23 patients had dose interruptions due to toxicity, most commonly for thrombocytopenia $(N=8)$, neutropenia $(N=6)$, and hypertension $(N=4)$. In addition, 13 patients required dose reductions for toxicity including hypertension $(N=4)$, and thrombocytopenia $(N=3)$. One patient permanently discontinued treatment owing to ataxia. A list of all grade 3 and 4 adverse events thought to be possibly, probably, or definitely related to treatment on study is given in Table 2. A summary of adverse events of any grade with the incidence of at least $10 \%$ that were at least possibly related to treatment on study is given in Supplementary Table A1.

Response and survival. The median PFS was 8.7 months (95\% CI 5.5-12.0) and the median OS was 14.0 months (95\% CI 10.0-17.9; Figures 1 and 2). Among the 36 evaluable patients, 19 (52.8\%) were progression free at 6 months, 8 of the 36 patients evaluable for response had confirmed partial responses, and an additional 16

Table 2. The incidence of grade 3 and 4 adverse events that were at least possibly related to treatment on study is shown

\begin{tabular}{|c|c|c|c|}
\hline & $\begin{array}{c}\text { Grade } 3 \\
(\%)\end{array}$ & $\begin{array}{c}\text { Grade } 4 \\
\text { (\%) }\end{array}$ & $\begin{array}{c}\text { All grades } \\
(\%)\end{array}$ \\
\hline \multicolumn{4}{|l|}{ Haematological } \\
\hline Neutropenia & 11 & 11 & 32 \\
\hline Thrombocytopenia & 5 & - & 32 \\
\hline Anaemia & 3 & - & 21 \\
\hline Febrile neutropenia & 3 & - & 3 \\
\hline \multicolumn{4}{|l|}{ Vascular } \\
\hline Hypertension & 16 & - & 47 \\
\hline \multicolumn{4}{|l|}{ Musculoskelatal } \\
\hline Generalised muscle weakness & 3 & - & 34 \\
\hline \multicolumn{4}{|l|}{ Gastrointestinal } \\
\hline Mucositis oral & 3 & - & 16 \\
\hline \multicolumn{4}{|l|}{ Metabolism/nutrition } \\
\hline Dehydration & 3 & - & 8 \\
\hline \multicolumn{4}{|l|}{ Infectious } \\
\hline Appendicitis & 3 & - & 3 \\
\hline \multicolumn{4}{|l|}{ Cardiac } \\
\hline Heart failure & 3 & - & 3 \\
\hline \multicolumn{4}{|l|}{ Neurological } \\
\hline Syncope & 3 & - & 3 \\
\hline \multicolumn{4}{|l|}{ Reproductive } \\
\hline Vaginal haemorrhage & 3 & - & 3 \\
\hline
\end{tabular}

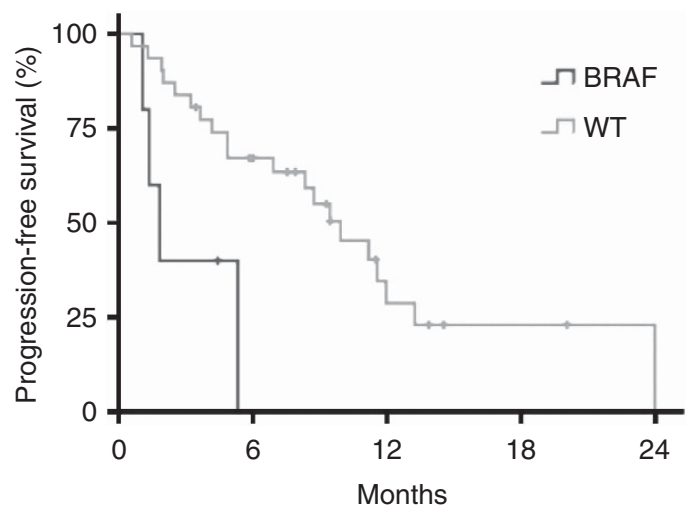

Figure 1. Kaplan-Meier curve showing progression-free survival in $\mathrm{BRAF}^{\mathrm{V} 600 \mathrm{E} / \mathrm{K}}$-mutant and $\mathrm{BRAF}^{\mathrm{V} 600 \mathrm{E} / \mathrm{K}}$ wild-type patients. 


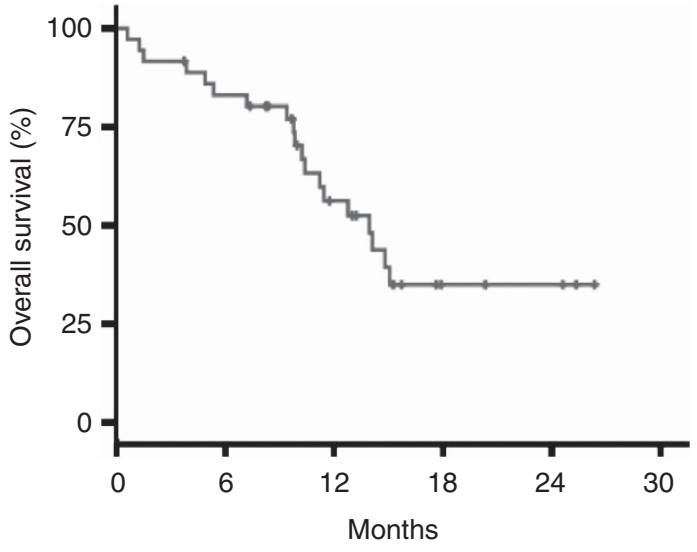

Figure 2. Kaplan-Meier curve showing overall survival in all evaluable patients.

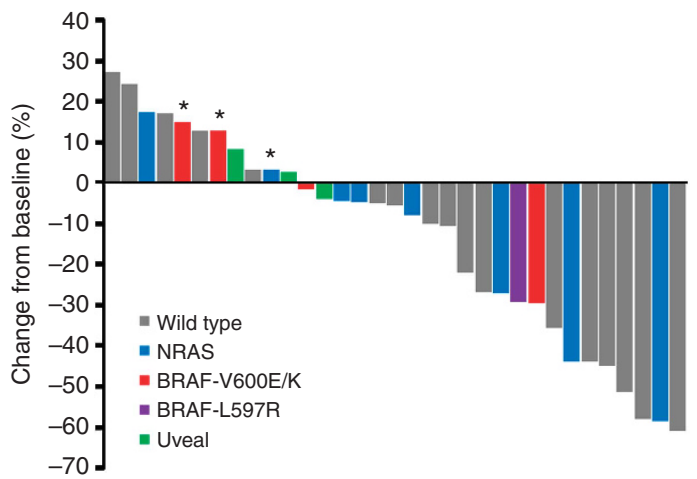

Figure 3. Waterfall plot shows the maximum change in the sum of tumour diameters by tumour genotype. An asterisk denotes progression of non-target lesions at first restaging scans.

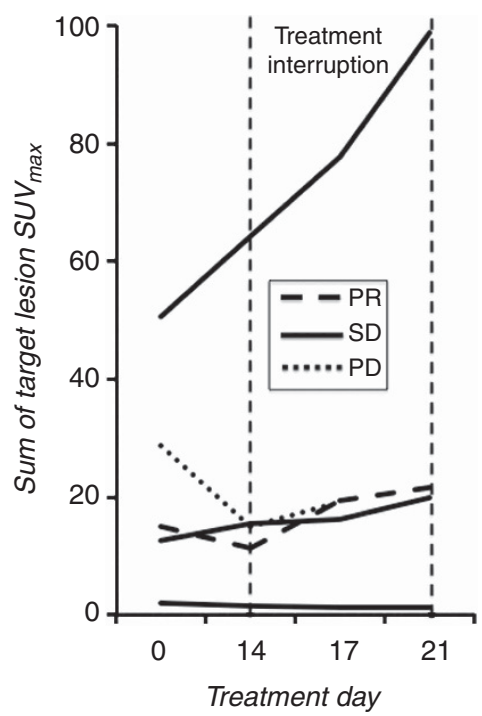

Figure 4. Sum of individual target lesion maximum ${ }^{18} \mathrm{~F}$-FLT SUV values in five patients undergoing serial ${ }^{18} \mathrm{~F}$-FLT-PET scans during the first treatment cycle. The treatment holiday began on day 14 and ended after day 21. Abbreviations: $P R=$ partial response, $S D=$ stable disease, $\mathrm{PD}=$ progression of disease as best response.

patients (44.4\%) had stabilisation of disease as the best response for an objective response rate of $22 \%$ (Figure 3 ) and a disease control rate of $66.7 \%$.
$3^{\prime}$-Deoxy- $3^{\prime}-{ }^{18}$ F-fluorothymidine-PET. Five patients completed both pre- and post-treatment ${ }^{18}$ F-FLT-PET scans (Figure 4). One patient had minimal ${ }^{18} \mathrm{~F}$-FLT uptake at baseline. In two patients, decreases in the sum of maximum ${ }^{18} \mathrm{~F}$-FLT uptake values were noted $(25.2 \%$ and $48.3 \%)$ on day 14 of axitinib therapy followed by increases of $43 \%$ and $28.2 \%$ from their nadirs, respectively, during the treatment holiday. Another patient had an increase of $23 \%$ on day 14 and an increase of $57 \%$ from baseline after the 7-day treatment holiday. A fifth patient did not undergo a follow-up ${ }^{18}$ F-FLT-PET study on day 14 , but had a $95 \%$ increase in ${ }^{18} \mathrm{~F}$-FLT uptake from baseline by the end of the treatment holiday.

Molecular analysis. Three patients on trial had $\mathrm{BRAF}^{\mathrm{V} 600 \mathrm{E}}$ mutations, three had BRAF $^{\mathrm{V} 600 \mathrm{~K}}$ mutations (including one inevaluable patient), and one patient had a BRAF ${ }^{\mathrm{L} 597 \mathrm{R}}$ mutation. All patients with BRAF mutant melanoma had cutaneous primaries. Among the 30 patients with no detectable BRAF mutations, 23 were tested for NRAS exon 1 and 2 mutations. Five cutaneous melanoma patients had an NRAS ${ }^{\mathrm{Q} 61 \mathrm{R}}$ mutations, two cutaneous melanoma patients had an NRAS ${ }^{\mathrm{Q} 61 \mathrm{~L}}$ mutations, and one mucosal melanoma patient had an NRAS ${ }^{\mathrm{G} 12 \mathrm{C}}$ mutation. Of the three patients with uveal melanoma, one was tested for GNAQ and GNA11, revealing a GNA11 ${ }^{\mathrm{Q} 209 \mathrm{~L}}$ mutation. In comparison with all other patients, $\mathrm{BRAF}^{\mathrm{V} 600 \mathrm{E} / \mathrm{K}}$ patients in this study had both shorter PFS (1.85 vs 9.92 months, $P<0.01$, Figure 1$)$ and shorter OS (10.2 vs 14.8 months, $P<0.05)$. One patient with a BRAF ${ }^{\mathrm{L} 597 \mathrm{R}}$ mutation had a PFS of 8.7 months and is still alive 21.3 months after initiating treatment on trial.

Additional subgroup analysis. Patients with elevated lactate dehydrogenase also had shorter PFS (4.9 vs 11.2 months, $P<0.05)$ and OS (9.8 months $v s$ median not reached, $P<0.01$ ) compared to patients with normal $\mathrm{LDH}$ at baseline. Patients with an ECOG performance status of 1 had shorter PFS than those with an ECOG performance status of 0 (5.3 vs 11.2 months, $P<0.05$ ), but there was no difference in OS between these groups (12.8vs 15.1 months, ns) There were no significant differences in PFS based on tumour M stage, patient age (above or below median age), prior treatment history, or tumour subtype (ocular, mucosal, cutaneous).

DISCUSSION

Although melanoma is a vascular tumour, attempts to add VEGF inhibition to chemotherapy have not been fruitful (Kim et al, 2012). In the current study, we show that administration of the potent VEGF receptor inhibitor, axitinib, followed by cytotoxic chemotherapy after a brief 7-day treatment holiday is highly active in metastatic melanoma, yielding a median PFS of 8.7 months and a median OS of 14.0 months. This PFS compares favourably with clinical trial data for paclitaxel/carboplatin without axitinib (median PFS = 4.1-4.5 months) (Hauschild et al, 2009; Kottschade et al, 2011; Kim et al, 2012) and to axitinib monotherapy (median PFS $=3.9$ months) (Fruehauf et al, 2011). The median PFS also compares favourably with combination of VEGF-targeted agents with chemotherapy such as carboplatin and paclitaxel with bevacizumab (median $\mathrm{PFS}=5.6$ months) (Kim et al, 2012), nab-paclitaxel with bevacizumab (median $\mathrm{PFS}=4$ months) (Spitler et al, 2015), and lenvatinib with oral temozolomide (median PFS $=5.4$ months) (Hong et al, 2012). Somewhat surprisingly, the median PFS of axitinib with paclitaxel/carboplatin exceeds the median PFS of several new agents approved for metastatic melanoma within the past 3 years: vemurafenib (median $\mathrm{PFS}=5.3$ months) (Chapman et al, 2011), dabrafenib (median $\mathrm{PFS}=5.1$ months) (Hauschild et al, 2012), and ipilimumab (median PFS $<3$ months) (Hodi et al, 2010; Robert et al, 2011). 
The median OS for axitinib with carboplatin and paclitaxel compares favourably to that of ipilimumab (median $\mathrm{OS}=13.2 \mathrm{vs}$ 10.1-11.2 months) despite the facts that patients in the current study tended to be older (median age $=64.5 v s 56.8-57.5$ years) and more likely to have an elevated baseline LDH (58\% vs 37.2$38.7 \%$ ), a negative prognostic factor for survival (Hodi et al, 2010; Robert et al, 2011). This is particularly remarkable as large randomised trials targeting VEGF in combination with chemotherapy have failed to demonstrate significant improvements in tumour response, PFS, or OS in patients treated with VEGF inhibitors (Hauschild et al, 2009; Kim et al, 2012). Although these cross-trial comparisons are hypothesis-generating only, these data support further testing of axitinib with carboplatin and paclitaxel in a randomised, phase III setting.

The clinical activity of axitinib with paclitaxel/carboplatin may be due the additive activity of axitinib with carboplatin and paclitaxel or synergistic antitumour activity that could be mediated by an increase in tumour proliferation induced by axitinib withdrawal. Axitinib is a particularly potent and selective VEGF receptor inhibitor with substantial single-agent activity in melanoma (Fruehauf et al, 2011). In a phase III trial in previously treated renal cell carcinoma, axitinib yielded a significantly longer investigator-assessed PFS than sorafenib, suggesting that axitinib is a more active agent in this setting (Motzer et al, 2013). Several studies have now demonstrated that potent small molecules kinase inhibitors including axitinib decrease tumour cell proliferation, potentially protecting them from the cytotoxic effects of chemotherapy that rely on cell cycling. The current data demonstrating decreased target lesion ${ }^{18}$ F-FLT uptake during treatment followed by increased uptake during the 7 -day treatment holiday in two patients are consistent with these findings. However, given the limited number of patients undergoing FLT-PET imaging in the present study, additional data would be required to determine whether the interruption in axitinib dosing before the administration of carboplatin and paclitaxel is truly essential for optimal benefit.

Our clinical data also suggest that the combination of axitinib administered in according to a 2-week-on and 1-week-off schedule with carboplatin and paclitaxel prolonged PFS without increasing the rate-objective tumour responses compared with historical data for axitinib or chemotherapy alone. Indeed, favourable PFS and OS were not always associated with objective tumour responses, and, although the overall response rate was only $22 \%$, over half of patients were progression free at 6 months.

This regimen was well tolerated with no grade 4 nonhaematologic toxicities. The only grade 3 non-haematologic toxicity noted in more than three patients was hypertension (six patients). Grade 3 and 4 haematologic toxicities were similar to those expected with cytotoxic chemotherapy alone including eight patients $(21 \%)$ developing grade 3 or 4 neutropenia, one patient with febrile neutropenia, two patients (5\%) with grade 3 thrombocytopenia, and one patient (3\%) developing grade 3 anaemia. One patient developed grade 3 congestive heart failure and another developed dose-limiting pancytopenia after brief exposures to axitinib alone. As neither patient received carboplatin and paclitaxel, these events do not suggest enhanced toxicity when axitinib is administered with carboplatin and paclitaxel.

The advent of potent BRAF inhibitors and BRAF inhibitor combinations that are only active against $\mathrm{BRAF}^{\mathrm{V} 600 \mathrm{E}}$ and $\mathrm{BRAF}^{\mathrm{V} 600 \mathrm{~K}}$ has underscored the need for therapies that are effective in BRAF wild-type melanoma. Axitinib with paclitaxel/carboplatin demonstrates substantial activity specifically in a BRAF wild-type metastatic melanoma population. Remarkably, axitinib with carboplatin and paclitaxel demonstrated a significantly shorter PFS in a small subset of patients with $\mathrm{BRAF}^{\mathrm{V} 600 \mathrm{E}}$ or BRAF ${ }^{\mathrm{V} 600 \mathrm{~K}}$ melanoma, two of whom were treatment naive. In contrast, one patient with $\mathrm{BRAF}^{\mathrm{L} 597 \mathrm{R}}$ melanoma demonstrated similar a PFS and OS to the
BRAF wild-type patients. He subsequently progressed on vemurafenib within 6 weeks suggesting that his disease may not have been dependent on aberrant BRAF signalling. Given these data and the availability of highly active BRAF inhibitors, further first-line testing of axitinib with carboplatin and paclitaxel should be restricted to BRAF wild-type melanoma.

In summary, axitinib with paclitaxel/carboplatin yielded prolonged disease control and survival in advanced BRAF wild-type metastatic melanoma with acceptable toxicity. The median PFS and OS of this combination compares favourably to clinical trial data for the recently approved agents vemurafenib and ipilimumab in metastatic melanoma and warrants further testing in randomised phase III setting.

\section{ACKNOWLEDGEMENTS}

This research was supported by Pfizer.

\section{REFERENCES}

Algazi AP, Soon CW, Daud AI (2010) Treatment of cutaneous melanoma: current approaches and future prospects. Cancer Manag Res 2: 197-211.

Chapman PB, Hauschild A, Robert C, Haanen JB, Ascierto P, Larkin J, Dummer R, Garbe C, Testori A, Maio M, Hogg D, Lorigan P, Lebbe C, Jouary T, Schadendorf D, Ribas A, O’Day SJ, Sosman JA, Kirkwood JM, Eggermont AM, Dreno B, Nolop K, Li J, Nelson B, Hou J, Lee RJ, Flaherty KT, McArthur GA (2011) Improved survival with vemurafenib in melanoma with BRAF V600E mutation. N Engl J Med 364: 2507-2516.

Demirkesen C, Büyükpinarbaşili N, Ramazanoğlu R, Oğuz O, Mandel NM, Kaner G (2006) The correlation of angiogenesis with metastasis in primary cutaneous melanoma: a comparative analysis of microvessel density, expression of vascular endothelial growth factor and basic fibroblastic growth factor. Pathology 38: 132-137.

Eisenhauer EA, Therasse P, Bogaerts J, Schwartz LH, Sargent D, Ford R, Dancey J, Arbuck S, Gwyther S, Mooney M, Rubinstein L, Shankar L, Dodd L, Kaplan R, Lacombe D, Verweij J (2009) New response evaluation criteria in solid tumours: revised RECIST guideline (version 1.1). Eur J Cancer 45: 228-247.

Falchook GS, Long GV, Kurzrock R, Kim KB, Arkenau TH, Brown MP, Hamid O, Infante JR, Millward M, Pavlick AC, O’Day SJ, Blackman SC, Curtis CM, Lebowitz P, Ma B, Ouellet D, Kefford RF (2012) Dabrafenib in patients with melanoma, untreated brain metastases, and other solid tumours: a phase 1 dose-escalation trial. Lancet 379: 1893-1901.

Flaherty KT, Puzanov I, Kim KB, Ribas A, McArthur GA, Sosman JA, O’Dwyer PJ, Lee RJ, Grippo JF, Nolop K, Chapman PB (2010) Inhibition of mutated, activated BRAF in metastatic melanoma. $N$ Engl J Med 363: 809-819.

Fruehauf J, Lutzky J, McDermott D, Brown CK, Meric J-B, Rosbrook B, Shalinsky DR, Liau KF, Niethammer AG, Kim S, Rixe O (2011) Multicenter, phase II study of axitinib, a selective second-generation inhibitor of vascular endothelial growth factor receptors 1, 2, and 3, in patients with metastatic melanoma. Clin Cancer Res 17: 7462-7469.

Graells J, Vinyals A, Figueras A, Llorens A, Moreno A, Marcoval J, Gonzalez FJ, Fabra A (2004) Overproduction of VEGF concomitantly expressed with its receptors promotes growth and survival of melanoma cells through MAPK and PI3K signaling. J Invest Dermatol 123: 1151-1161.

Hauschild A, Agarwala SS, Trefzer U, Hogg D, Robert C, Hersey P, Eggermont A, Grabbe S, Gonzalez R, Gille J, Peschel C, Schadendorf D, Garbe C, O'Day S, Daud A, White JM, Xia C, Patel K, Kirkwood JM, Keilholz U (2009) Results of a phase III, randomized, placebo-controlled study of sorafenib in combination with carboplatin and paclitaxel as second-line treatment in patients with unresectable stage III or stage IV melanoma. J Clin Oncol 27: 2823-2830.

Hauschild A, Grob J-J, Demidov LV, Jouary T, Gutzmer R, Millward M, Rutkowski P, Blank CU, Miller Jr WH, Kaempgen E, Martín-Algarra S, Karaszewska B, Mauch C, Chiarion-Sileni V, Martin AM, Swann S, Haney P, Mirakhur B, Guckert ME, Goodman V, Chapman PB (2012) Dabrafenib in BRAF-mutated metastatic melanoma: a multicentre, open-label, phase 3 randomised controlled trial. Lancet 380: 358-365. 
Hodi FS, O'Day SJ, McDermott DF, Weber RW, Sosman JA, Haanen JB, Gonzalez R, Robert C, Schadendorf D, Hassel JC, Akerley W, van den Eertwegh AJ, Lutzky J, Lorigan P, Vaubel JM, Linette GP, Hogg D, Ottensmeier CH, Lebbé C, Peschel C, Quirt I, Clark JI, Wolchok JD, Weber JS, Tian J, Yellin MJ, Nichol GM, Hoos A, Urba WJ (2010) Improved survival with ipilimumab in patients with metastatic melanoma. N Engl J Med 363: 711-723.

Hoh C, Infante JR, Burris HA, Tarazi JC, Kim S, Rosbrook B, Reid TR (2011) Axitinib inhibition of [ $18 \mathrm{~F}$ ] fluorothymidine (FLT) uptake in patients (pts) with colorectal cancer (CRC): Implications for cytotoxic chemotherapy combinations. J Clin Oncol 29(Suppl): abstr 3591.

Hong DS, Andresen C, Mink J, Ren M, O’Brien James P, Nguyen Ly Minh, Falchook Gerald Steven, Kurzrock Razelle, John J Nemunaitis (2012) A phase IB study of lenvatinib (E7080) in combination with temozolomide for treatment of advanced melanoma. J Clin Oncol 30(Suppl): abstr 8594

Hurwitz H, Fehrenbacher L, Novotny W, Cartwright T, Hainsworth J, Heim W, Berlin J, Baron A, Griffing S, Holmgren E, Ferrara N, Fyfe G, Rogers B, Ross R, Kabbinavar F (2004) Bevacizumab plus irinotecan, fluorouracil, and leucovorin for metastatic colorectal cancer. N Engl J Med 350: 2335-2342.

Jemal A, Siegel R, Xu J, Ward E (2010) Cancer Statistics, 2010. CA Cancer J Clin 60: 277-300.

Kaplan EL, Meier P (1958) Nonparametric estimation from incomplete observations. J Am Stat Assoc 53: 457.

Kim KB, Sosman JA, Fruehauf JP, Linette GP, Markovic SN, McDermott DF, Weber JS, Nguyen H, Cheverton P, Chen D, Peterson AC, Carson 3rd WE, O'Day SJ (2012) BEAM: a randomized phase II study evaluating the activity of bevacizumab in combination with carboplatin plus paclitaxel in patients with previously untreated advanced melanoma. J Clin Oncol 30: 34-41.

Kottschade LA, Suman VJ, Amatruda 3rd T, McWilliams RR, Mattar BI, Nikcevich DA, Behrens R, Fitch TR, Jaslowski AJ, Markovic SN (2011) A phase II trial of nab-paclitaxel (ABI-007) and carboplatin in patients with unresectable stage IV melanoma: a North Central Cancer Treatment Group Study, N057E (1). Cancer 117: 1704-1710.

Motzer RJ, Hutson TE, Tomczak P, Michaelson MD, Bukowski RM, Oudard S, Negrier S, Szczylik C, Pili R, Bjarnason GA, Garcia-del-Muro X, Sosman JA, Solska E, Wilding G, Thompson JA, Kim ST, Chen I, Huang X, Figlin RA (2009) Overall survival and updated results for sunitinib compared with interferon alfa in patients with metastatic renal cell carcinoma. J Clin Oncol 27: 3584-3590.

Motzer RJ, Escudier B, Tomczak P, Hutson TE, Michaelson MD, Negrier S, Oudard S, Gore ME, Tarazi J, Hariharan S, Chen C, Rosbrook B, Kim S, Rini BI (2013) Axitinib versus sorafenib as second-line treatment for advanced renal cell carcinoma: overall survival analysis and updated results from a randomised phase 3 trial. Lancet Oncol 14: 552-562.

Oku T, Tjuvajev JG, Miyagawa T, Sasajima T, Joshi A, Joshi R, Finn R, Claffey KP, Blasberg RG (1998) Tumor growth modulation by sense and antisense vascular endothelial growth factor gene expression: effects on angiogenesis, vascular permeability, blood volume, blood flow, fluorodeoxyglucose uptake, and proliferation of human melanoma intracerebral xenografts. Cancer Res 58: 4185-4192.

Perren TJ, Swart AM, Pfisterer J, Ledermann JA, Pujade-Lauraine E, Kristensen G, Carey MS, Beale P, Cervantes A, Kurzeder C, du Bois A,
Sehouli J, Kimmig R, Stähle A, Collinson F, Essapen S, Gourley C, Lortholary A, Selle F, Mirza MR, Leminen A, Plante M, Stark D, Qian W, Parmar MK, Oza AM (2011) A phase 3 trial of bevacizumab in ovarian cancer. N Engl J Med 365: 2484-2496.

Rao RD, Holtan SG, Ingle JN, Croghan GA, Kottschade LA, Creagan ET, Kaur JS, Pitot HC, Markovic SN (2006) Combination of paclitaxel and carboplatin as second-line therapy for patients with metastatic melanoma. Cancer 106: 375-382.

Rini BI, Escudier B, Tomczak P, Kaprin A, Szczylik C, Hutson TE, Michaelson MD, Gorbunova VA, Gore ME, Rusakov IG, Negrier S, Ou YC, Castellano D, Lim HY, Uemura H, Tarazi J, Cella D, Chen C, Rosbrook B, Kim S, Motzer RJ (2011) Comparative effectiveness of axitinib versus sorafenib in advanced renal cell carcinoma (AXIS): a randomised phase 3 trial. Lancet 378: 1931-1939.

Robert C, Thomas L, Bondarenko I, O’Day S, Weber J, Garbe C, Lebbe C, Baurain J-F, Testori A, Grob J-J, Davidson N, Richards J, Maio M, Hauschild A, Miller Jr WH, Gascon P, Lotem M, Harmankaya K, Ibrahim R, Francis S, Chen TT, Humphrey R, Hoos A, Wolchok JD (2011) Ipilimumab plus dacarbazine for previously untreated metastatic melanoma. N Engl J Med 364: 2517-2526.

Saltz LB, Clarke S, Díaz-Rubio E, Scheithauer W, Figer A, Wong R, Koski S, Lichinitser M, Yang T-S, Rivera F, Couture F, Sirzén F, Cassidy J (2008) Bevacizumab in combination with oxaliplatin-based chemotherapy as first-line therapy in metastatic colorectal cancer: a randomized phase III study. J Clin Oncol 26: 2013-2019.

Salven P, Heikkilä P, Joensuu H (1997) Enhanced expression of vascular endothelial growth factor in metastatic melanoma. Br J Cancer 76: 930-934.

Sandler A, Gray R, Perry MC, Brahmer J, Schiller JH, Dowlati A, Lilenbaum R, Johnson DH (2006) Paclitaxel-carboplatin alone or with bevacizumab for non-small-cell lung cancer. N Engl J Med 355: 2542-2550.

Sosman JA, Kim KB, Schuchter L, Gonzalez R, Pavlick AC, Weber JS, McArthur GA, Hutson TE, Moschos SJ, Flaherty KT, Hersey P, Kefford R, Lawrence D, Puzanov I, Lewis KD, Amaravadi RK, Chmielowski B, Lawrence HJ, Shyr Y, Ye F, Li J, Nolop KB, Lee RJ, Joe AK, Ribas A (2012) Survival in BRAF V600-mutant advanced melanoma treated with vemurafenib. $N$ Engl J Med 366: 707-714.

Spitler LE, Boasberg P, Day SO, Hamid O, Cruickshank S, Mesko S, Weber RW (2015) Phase II study of nab-paclitaxel and bevacizumab as first-line therapy for patients with unresectable stage III and IV melanoma. Am J Clin Oncol 38: 61-67.

Ugurel S, Rappl G, Tilgen W, Reinhold U (2001) Increased serum concentration of angiogenic factors in malignant melanoma patients correlates with tumor progression and survival. J Clin Oncol 19: 577-583.

This work is published under the standard license to publish agreement. After 12 months the work will become freely available and the license terms will switch to a Creative Commons AttributionNonCommercial-Share Alike 3.0 Unported License.

Supplementary Information accompanies this paper on British Journal of Cancer website (http://www.nature.com/bjc) 